Supporting Information to

\title{
Thio-click modification of poly[2-(3-butenyl)-2-oxazoline]
}

\author{
Anja Gress, Antje Völkel, and Helmut Schlaad* \\ Max Planck Institute of Colloids and Interfaces, Colloid Department \\ Research Campus Golm, 14424 Potsdam, Germany
}

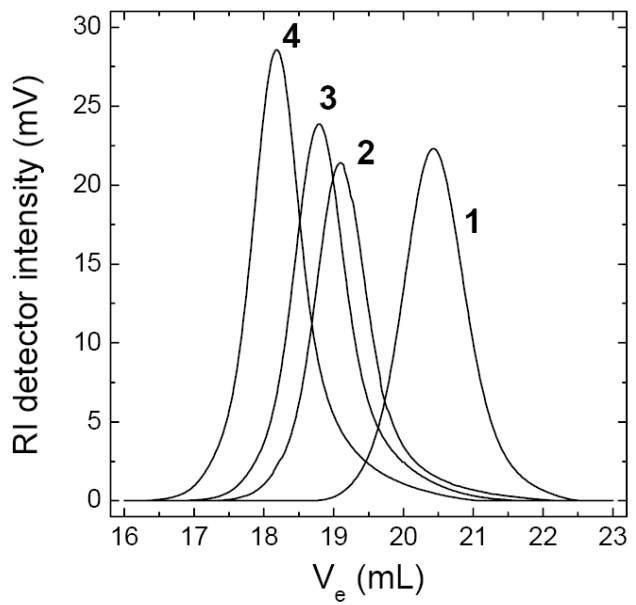

Figure SI-1. Size exclusion chromatograms of poly[2-(3-butenyl)-2-oxazoline]s 1-4 in THF.
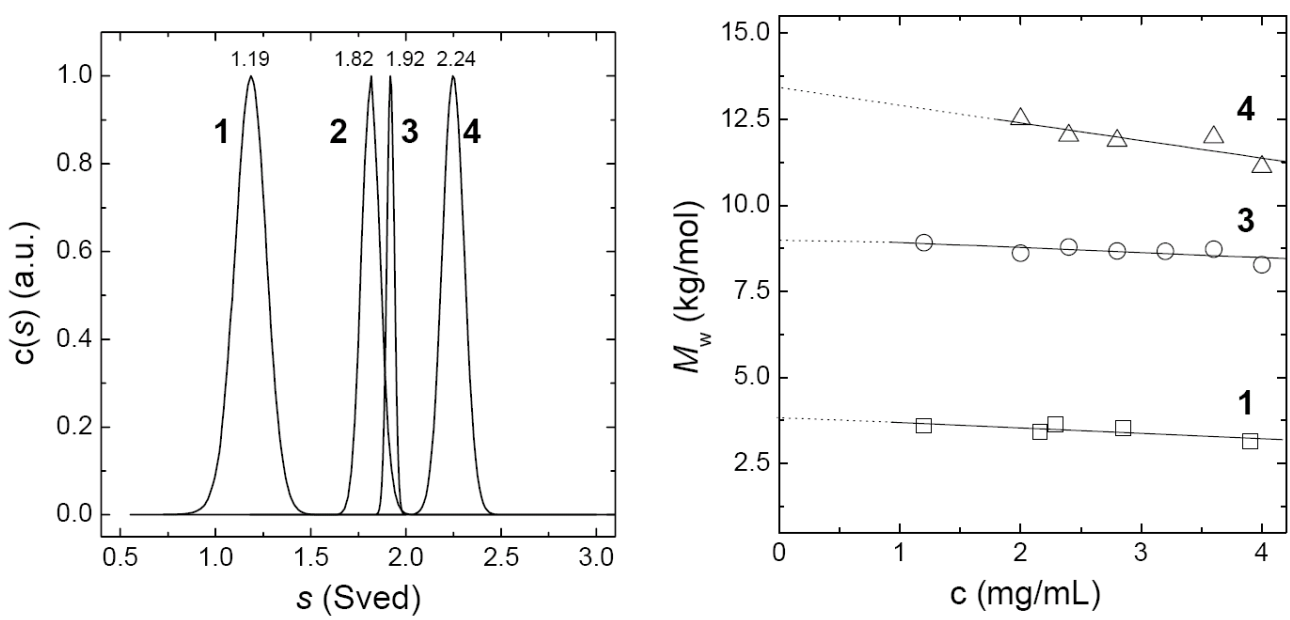

Figure SI-2. Left: Diffusion-corrected sedimentation coefficient distributions $(\mathrm{c}(s))$ of poly[2(3-butenyl)-2-oxazoline]s $\mathbf{1 - 4}$ in methanol at $60 \mathrm{~K} \mathrm{rpm}, 25{ }^{\circ} \mathrm{C}$. Right: Weight-average molecular weights $\left(M_{\mathrm{w}}\right)$ of $\mathbf{1}, \mathbf{3}$, and $\mathbf{4}$ as determined by AUC equilibrium measurements in methanol at different concentrations and at $35 \mathrm{~K} / 30 \mathrm{~K} \mathrm{rpm}, 25^{\circ} \mathrm{C}$. 


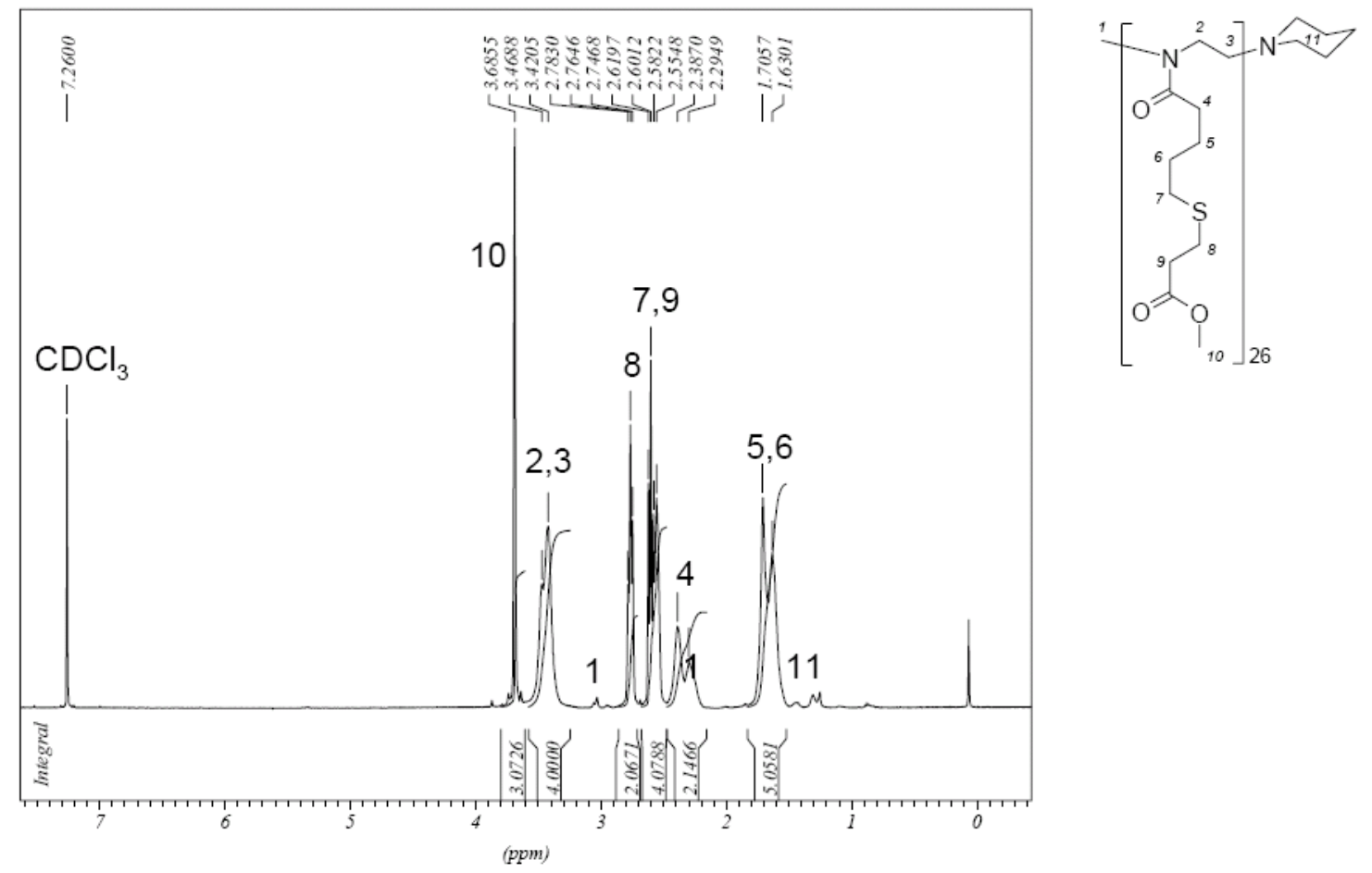

Figure SI-3. ${ }^{1} \mathrm{H}$ NMR spectrum (400.1 MHz) of modified poly[2-(3-butenyl)-2-oxazoline] 1a in $\mathrm{CDCl}_{3}$.
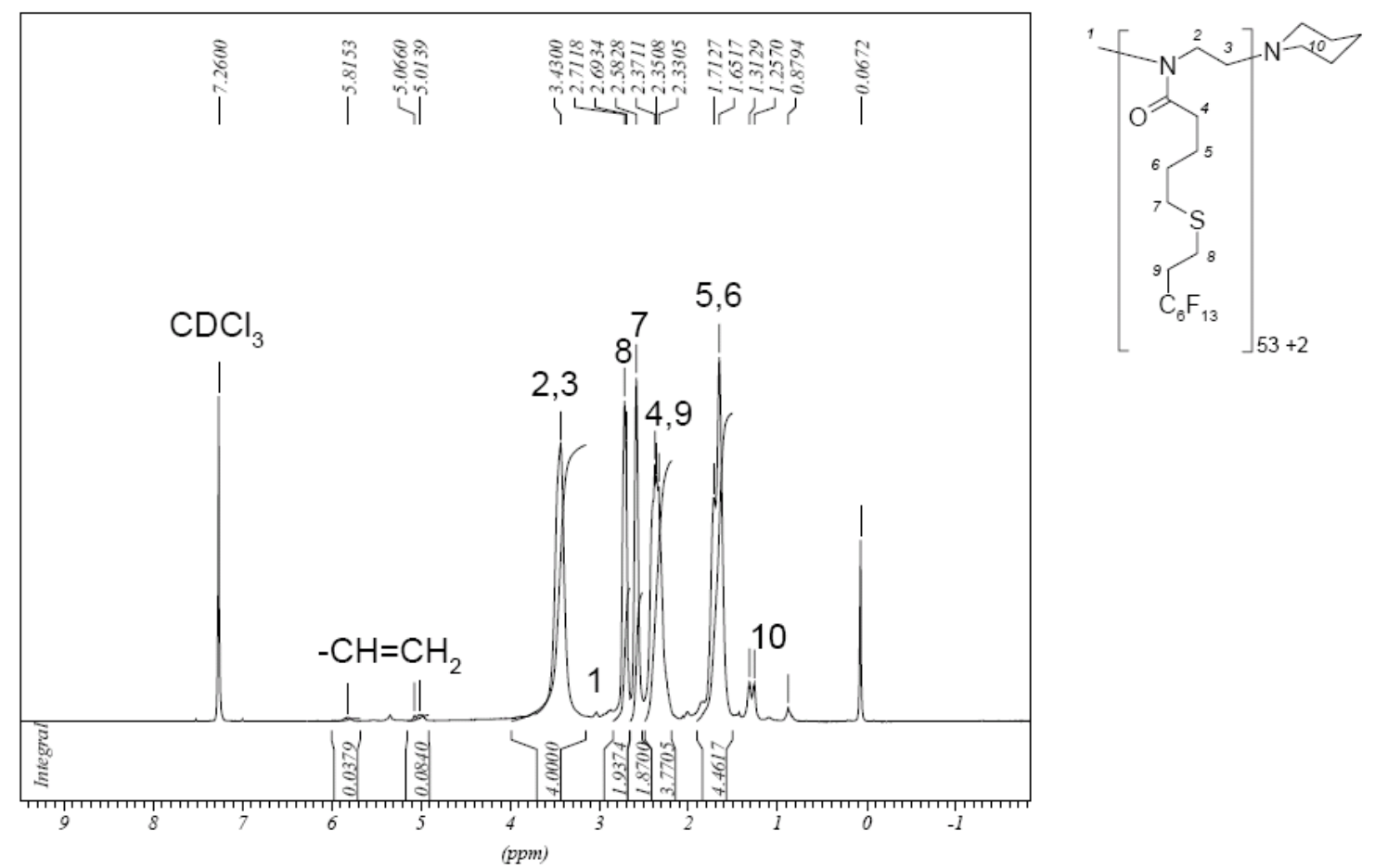

Figure SI-4. ${ }^{1} \mathrm{H}$ NMR spectrum (400.1 MHz) of modified poly[2-(3-butenyl)-2-oxazoline] 2b in $\mathrm{CDCl}_{3}$. 


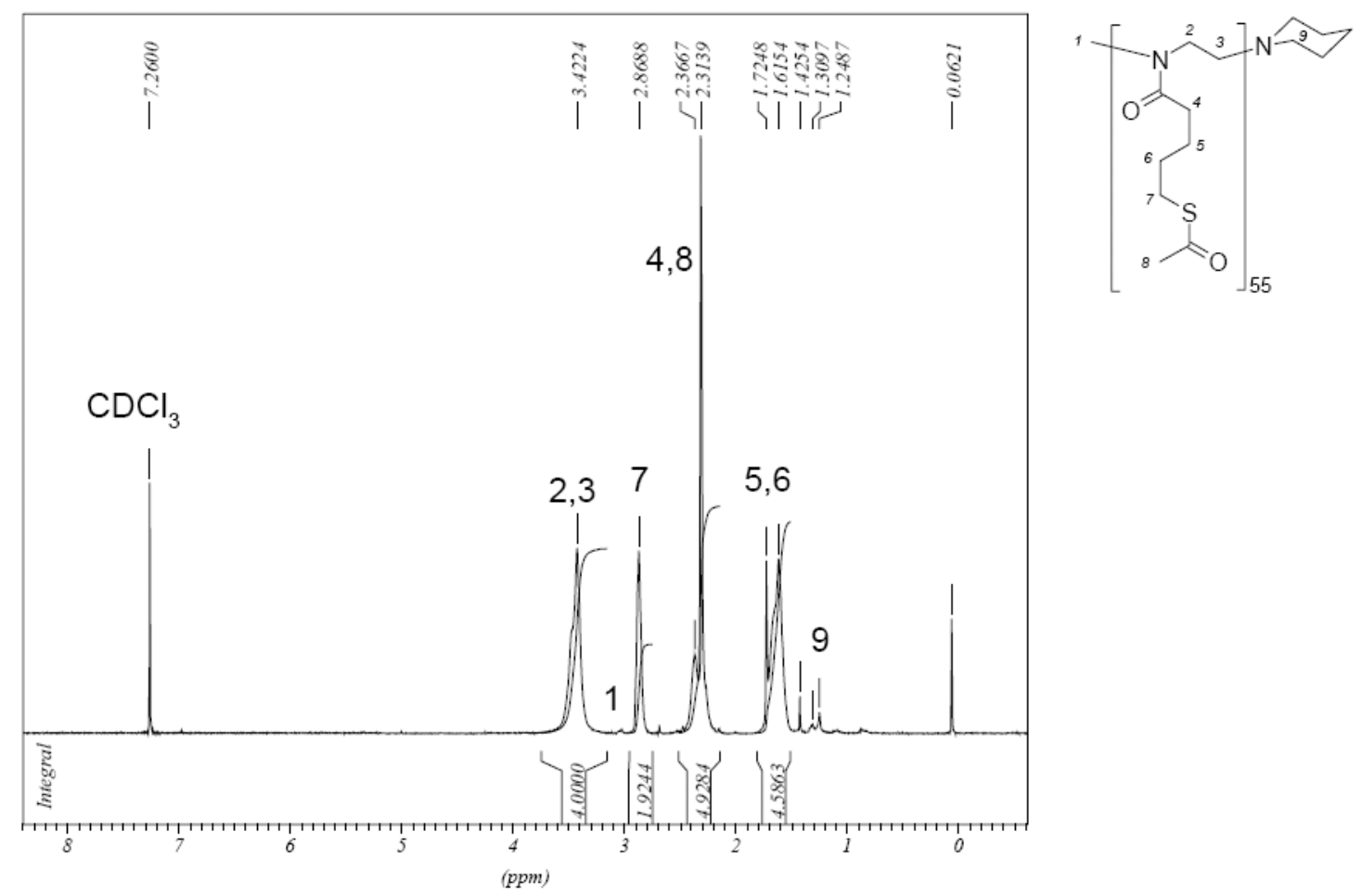

Figure SI-5. ${ }^{1} \mathrm{H}$ NMR spectrum (400.1 MHz) of modified poly[2-(3-butenyl)-2-oxazoline] 2d in $\mathrm{CDCl}_{3}$.
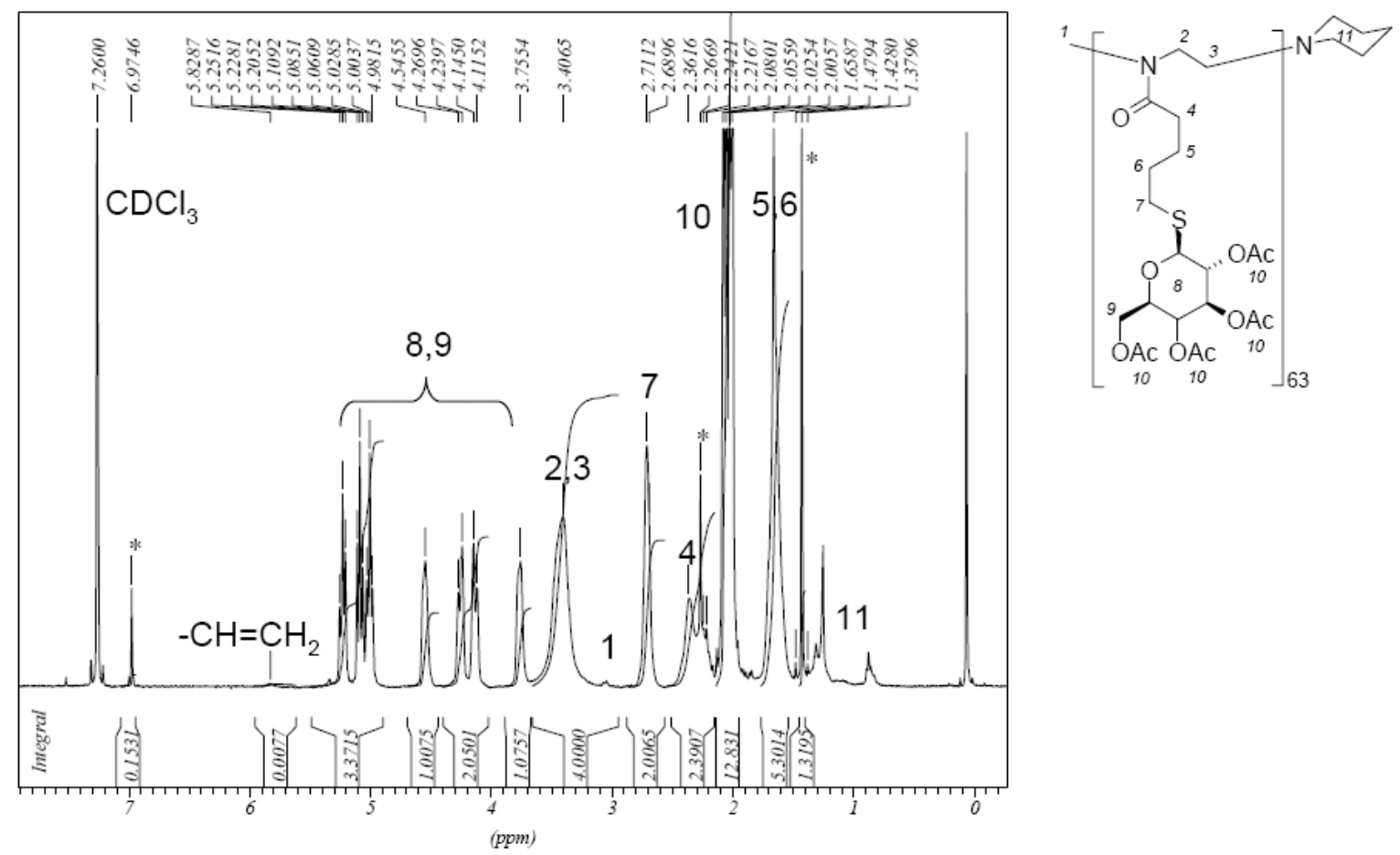

Figure SI-6. ${ }^{1} \mathrm{H}$ NMR spectrum (400.1 MHz) of modified poly[2-(3-butenyl)-2-oxazoline] 3e in $\mathrm{CDCl}_{3}$; signals labeled with * are from BHT. 


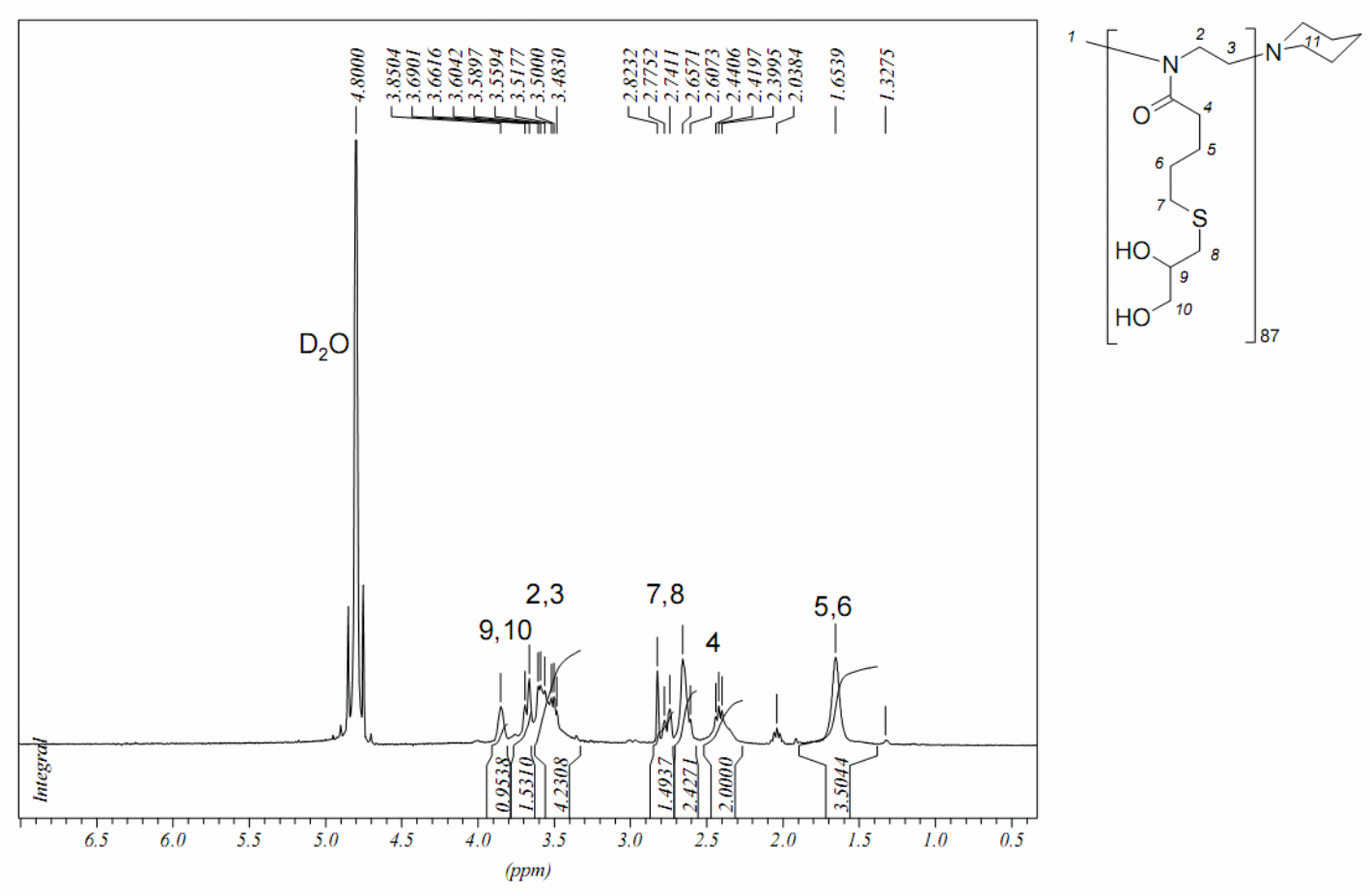

Figure SI-7. ${ }^{1} \mathrm{H}$ NMR spectrum (400.1 MHz) of modified poly[2-(3-butenyl)-2-oxazoline] 4c in $\mathrm{D}_{2} \mathrm{O}$.

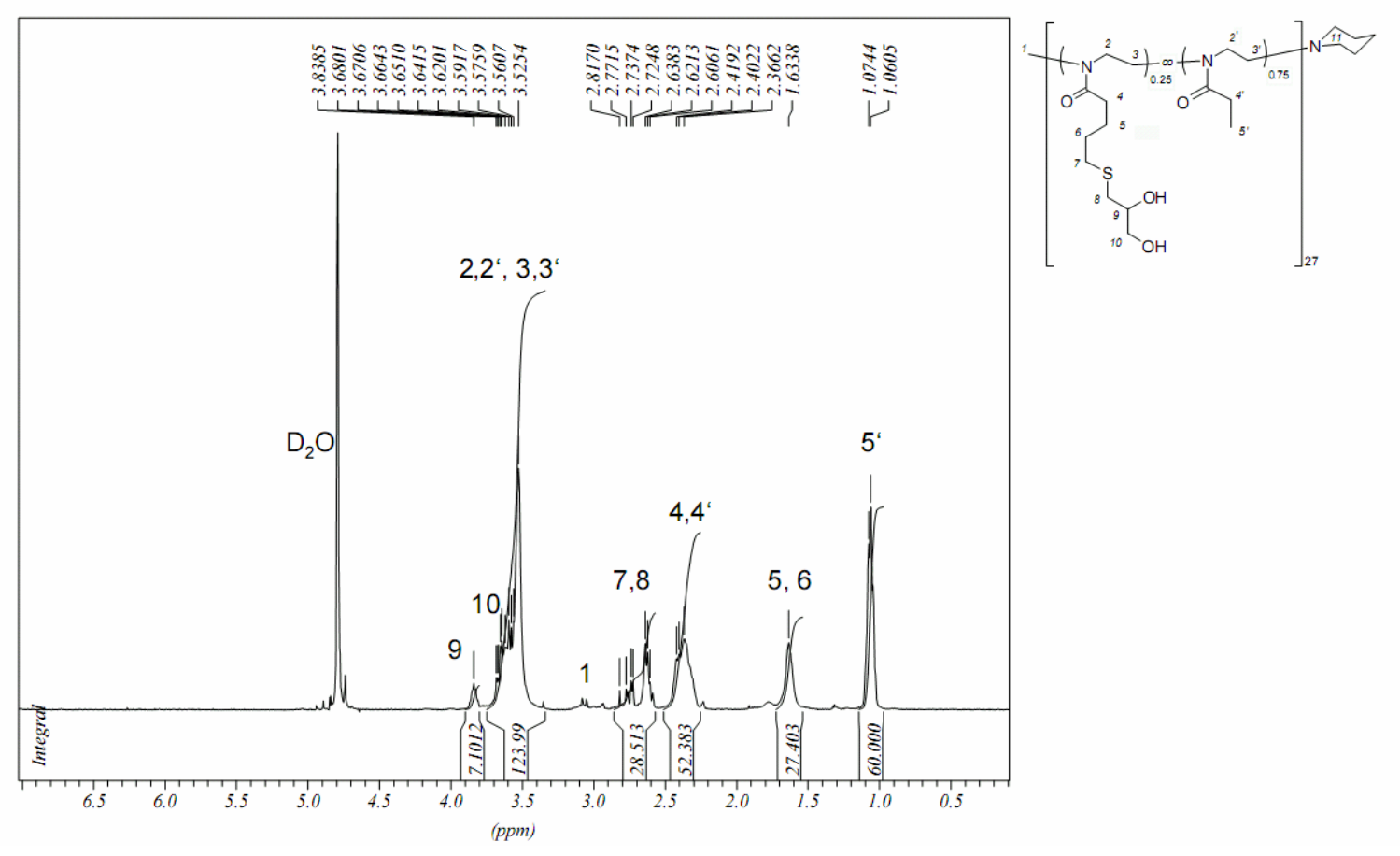

Figure SI-8. ${ }^{1}$ H NMR spectrum (400.1 MHz) of modified poly[(2-(3-butenyl)-2-oxazoline)co-(2-ethyl-2-oxazoline)] $\mathbf{5 c}$ in $\mathrm{D}_{2} \mathrm{O}$. 


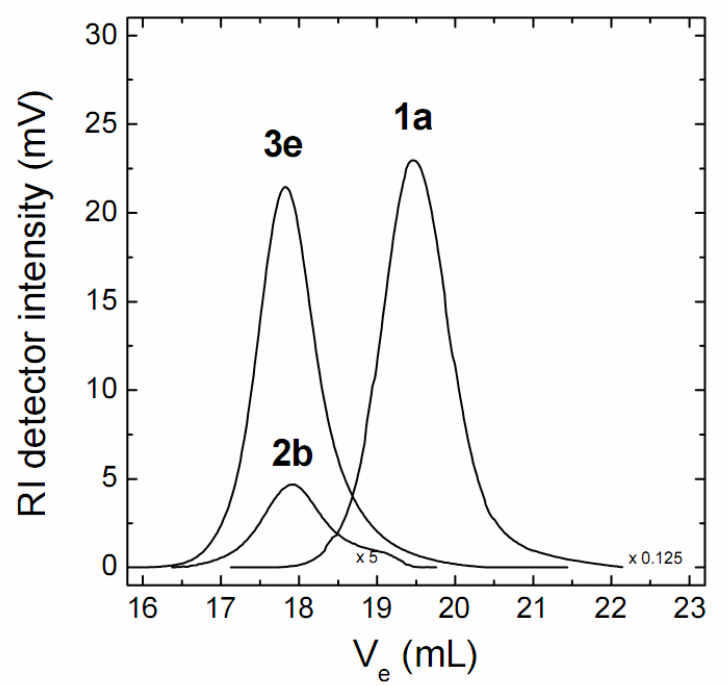

Figure SI-9. Size exclusion chromatograms of modified poly[2-(3-butenyl)-2-oxazoline]s 1a, $\mathbf{2 b}$, and $\mathbf{3 e}$ in THF. 